\title{
Energia Digestível para Larvas de Tilápia-do-Nilo (Oreochromis niloticus) na Fase de Reversão Sexual
}

\section{Wilson Rogério Boscolo ${ }^{1}$, Altevir Signor ${ }^{2}$, Aldi Feiden ${ }^{3}$, Robie Allan Bombardelli ${ }^{4}$, Arcangelo Augusto Signor ${ }^{1}$, Adilson Reidel ${ }^{5}$}

\begin{abstract}
RESUMO - Este trabalho foi realizado com o objetivo de se avaliar o efeito de diferentes níveis de energia digestível na ração sobre o desempenho de larvas de tilápia-do-nilo (Oreochromis niloticus), durante a fase de reversão sexual. Foram utilizadas 375 larvas com

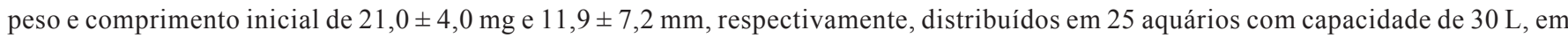
um delineamento experimental inteiramente casualizado, composto por cinco tratamentos e cinco repetições, em que a unidade experimental foi considerada como um aquário contendo 15 larvas. As rações foram formuladas de modo a conterem 3.300; $3.525 ; 3.750 ; 3.975$ e 4.200 $\mathrm{kcal} / \mathrm{kg}$ de energia digestível e serem isoprotéicas (38,6\% de proteína digestível). Os animais foram alimentados ad libitum cinco vezes ao dia. Ao final do experimento, foram analisadas as médias de peso final (PF), sobrevivência (SO), fator de condição (FC) e comprimento final (CF). O aumento de ED nas rações proporcionou redução linear no PF e CF dos peixes. Não foram observadas diferenças na $\mathrm{SO}$ e FC dos peixes nos diferentes tratamentos. Conclui-se que o aumento nos níveis de energia digestível em rações para larvas de tilápia-do-nilo durante a reversão sexual proporciona redução no desempenho.
\end{abstract}

Palavras-chave: desempenho, energia digestível, exigência nutricional, larvicultura, peixes, tilápia

\section{Digestible Energy for Nile Tilapia (Oreochromis niloticus) Larvae in the Sexual Reversion Phase}

\begin{abstract}
This experiment was conducted to evaluate different levels of digestible energy on the performance of Nile tilapia larvae (Oreochromis niloticus) during the sexual reversion phase. Three hundred and seventy-five larvae with initial average length and weight of $21.0 \pm 4.0 \mathrm{mg}$ and $1.19 \pm 0.72 \mathrm{~cm}$, respectively, were allotted to $2530 \mathrm{~L}$-aquarium. A completely randomized design with five treatments and five replicates was used. The aquarium with 15 larvae was the experimental unit. The diets were formulated to contain levels of $3,300,3,525,3,750,3,975$, and 4,200 kcal/kg of digestible energy and to be isoprotein (38.6\% digestible protein). The animals were fed ad libitum five times a day. At the end of the experiment, the averages of weight (PF), survival rate (SO), condition factor (FC) and length (CF) were analyzed. Linear reduction of fishes PF and CF, as the dietary digestible energy levels increased, was observed. No differences on fish SO and FC of different treatments were observed. Deleterious effects on performance due to the increasing dietary digestible energy levels were noticed for Nile tilapia larvae during the sexual reversion.
\end{abstract}

Key Words: digestible energy, Oreochromis niloticus, larvae, nutritional requirements, performance, tilapia

\section{Introdução}

As tilápias representam o segundo maior grupo de peixes cultivados no mundo, por apresentarem crescimento rápido e rusticidade (Hayashi et al., 1999a), além de fácil manipulação de sexo e carne de ampla aceitação pelo mercado consumidor, em razão da inexistência de espinhos em forma de " $y$ " em seu filé (Hildsorf, 1995), tornando esta espécie apropriada para a indústria de filetagem (Boscolo, 2003). O sistema de "pesque-pague" no Brasil ampliou muito a sua demanda nos últimos anos, sendo responsável pelo incremento inicial da produção piscícola nacional (Borghetti \& Ostrensky, 1998). Em virtude da importância da tilápia para a aqüicultura, muitos aspectos de sua nutrição são estudados (Degani \& Revach 1991; Shiau, 1997; Boscolo et al., 2002).

A participação de fontes energéticas é de suma importância, pois a relação energia/proteína deve ser adequada, para que os peixes apresentem boas taxas de crescimento (Page \& Andrews, 1973; Chou \& Shiau, 1996). A formulação de rações com elevada taxa de energia resulta na baixa ingestão de proteína e de nutrientes essenciais, ocorrendo depósito de

\footnotetext{
${ }^{1}$ Professor Adjunto do curso de Engenharia de Pesca - UNIOESTE - Campus ToledolParaná. E.mail: wrboscolo@unioeste.br

2 Engenheiro de Pesca, Mestrado em Aqüicultura - CAUNESP - Jaboticabal, SP. E.mail: altevirsignor@bol.com.br

3 Professor Adjunto do curso de Engenharia de Pesca - UNIOESTE - Campus ToledolParaná. E.mail: aldi@unioeste.br

4 Professor do curso de Engenharia de Pesca - UNIOESTE - Campus ToledolParaná. E.mail: rabombardelli@unioeste.br

${ }^{5}$ Engenheiro de Pesca - Doutorando em Aqüicultura- Caunesp - JaboticaballSão Paulo. E.mail: areidel@unioeste.br
} 
gordura visceral em tilápias (Boscolo et al., 2002; Meurer et al., 2002) e corporal em várias espécies (MacGoogan \& Reigh, 1996; Mukhopadhyay \& Ray, 1997). Por outro lado, a baixa taxa de energia não-protéica na dieta faz com que os peixes sintetizem ácidos graxos a partir de proteínas e apresentem elevada conversão alimentar (Lovell, 1989), provocando aumento de excreção de amônia no ambiente aquático, além de encarecer as rações, pois os alimentos protéicos são os mais onerosos.

A utilização de lipídios como fonte de energia varia conforme a espécie, dependendo de seu hábito alimentar, sendo os peixes carnívoros mais eficientes na utilização dos lipídios que os onívoros (Wilson, 1998). Os lipídeos são fontes energéticas facilmente encontradas no mercado, apresentando alta taxa de energia e considerável quantidade de ácidos graxos essenciais (Steffens, 1987; Meurer et al., 2002). Além de níveis adequados de lipídeos, é também de suma importância o perfil de ácidos graxos essenciais na dieta para a promoção do bom crescimento (Sanches, 2004). Segundo o NRC (1993), a tilápia-do-nilo necessita, no mínimo, de $0,5 \%$ de ácido linoléico na ração.

$\mathrm{O}$ fornecimento de lipídeos em dietas para peixes determina melhoria na conversão alimentar (Martino et al., 2002), e, segundo Jauncey (2000), apresenta custo acessível e alto nível energético, podendo influenciar no consumo de alimento (Lee et al., 2002) e melhorar a digestibilidade de alimentos vegetais (Belal \& Assem, 1995). El-Dahhar \& El-Shzly (1993) afirmam que a tilápia não utiliza eficientemente os lipídios da dieta como fonte energética. Chou \& Shiau (1996) e Meurer et al. (2002) destacam que esta espécie não utiliza eficientemente a energia suplementar proveniente do lipídeo em níveis acima de $5 \%$ de inclusão na ração.

Boscolo et al. (2002) determinaram para o óleo de soja coeficientes de digestibilidade aparente (CDA) de $89,85 \%$, com energia digestível de $8.485 \mathrm{kcal} / \mathrm{kg}$, demonstrando que a tilápia absorve eficientemente a energia desta fonte alimentar. Valor semelhante foi encontrado por Hanley (1987), avaliando o CDA da EB do óleo de vísceras de aves. No entanto, é de fundamental importância avaliar a exigência energética de tilápia-do-nilo (Oreochromis niloticus) na fase larval, para se obter alevinos em quantidade e qualidade para as fases subseqüentes.

Este trabalho foi conduzido para se avaliar o efeito da inclusão de diferentes níveis de energia digestível na dieta sobre o desempenho de larvas de tilápia-donilo (O. niloticus) durante a fase de reversão sexual.

\section{Material e Métodos}

O trabalho foi realizado no Laboratório de Aqüicultura da Universidade Estadual do Oeste do Paraná/Campus de Toledo no período de 20 de março a 16 de abril de 2004. Foram utilizadas 375 pós-larvas de tilápias-do-nilo( $O$. niloticus $)$ com peso e comprimento inicial de $21 \pm 4 \mathrm{mg}$ e 11,9 \pm 7,2 $\mathrm{mm}$, respectivamente, distribuídas em 25 aquários com volume útil de $30 \mathrm{~L}$, em delineamento inteiramente casualisado, com cinco tratamentos e cinco repetições, sendo a unidade experimental constituída por um aquário com 15 larvas.

Os aquários possuíam sistema de aeração individual ligados a um soprador de ar central, com aquecedores individuais. Diariamente, foi realizada a sifonagem do fundo dos aquários às 8 e 17h, antes da primeira e última alimentação, para retirada de sobras de ração e de fezes, substituindo-se cerca de $10 \%$ do volume total por vez até o $11^{\circ}$ dia, e, após este período, de $35 \%$ por vez.

Os alimentos foram processados em um moinho tipo faca com peneira de malha de $0,5 \mathrm{~mm}$. As rações experimentais foram formuladas com níveis de 3.300, $3.525,3.750,3.975$ e $4.200 \mathrm{kcal} / \mathrm{kg}$ de energia digestível, como proposto por Boscolo et al. (2002) e Meurer et al. (2002), para serem isocalcíticas, isofosfóricas e isoprotéicas (38,6\% de proteína digestível), segundo Hayashi et al. (2002) (Tabelas 1 e 2). O arraçoamento foi ad libtum e realizado cinco vezes ao dia às $8 \mathrm{~h}$, $10 \mathrm{~h} 30,13 \mathrm{~h}, 15 \mathrm{~h} 30$ e $17 \mathrm{~h}$.

Os parâmetros $\mathrm{pH}$, condutividade elétrica $(\mu \mathrm{S} / \mathrm{cm})$ e oxigênio dissolvido $(\mathrm{mg} / \mathrm{L})$ foram mensurados semanalmente, em aparelhos eletrônicos portáteis, enquanto a temperatura $\left({ }^{\circ} \mathrm{C}\right)$ foi medida diariamente pela manhã $(8 \mathrm{~h})$ e à tarde (17h), antes das sifonagens.

No final do período experimental, os peixes foram mantidos em jejum por 12 horas. Após este período, foram efetuadas as medidas individuais de peso $(\mathrm{mg})$ e comprimento total $(\mathrm{mm})$ dos peixes de cada unidade experimental. Foram avaliadas as médias de comprimento final (CF), sobrevivência $(\%)(\mathrm{SO})$, fator de condição (FC) e o peso final médio (PF).

Os dados obtidos foram submetidos à análise estatística a 5\% de variância pelo programa estatístico SAEG (Sistema de Análises Estatísticas e Genéticas) e, em caso de diferenças, foi aplicada análise de regressão linear (UFV, 1997). 
Tabela 1 - Composição percentual dos ingredientes das rações experimentais (matéria natural) Table 1 - Ingredient composition of experimental diets as-fed basis (\%) ${ }^{1}$

\begin{tabular}{|c|c|c|c|c|c|}
\hline \multirow[t]{2}{*}{$\begin{array}{l}\text { Ingrediente } \\
\text { Ingredient }\end{array}$} & \multicolumn{5}{|c|}{$\begin{array}{c}\text { Nível de energia digestível ( } \mathrm{kcal} / \mathrm{kg}) \\
\text { Digestible energylevel }\end{array}$} \\
\hline & 3300 & 3525 & 3750 & 3975 & 4200 \\
\hline Calcáreo calcítico (Limestone) & 0,731 & 0,55 & 0,37 & 0,18 & 0,00 \\
\hline Farinha de resíduos de tilápias (Tilapia by-products) & 14,37 & 15,74 & 17,11 & 18,47 & 19,48 \\
\hline Farinha de visceras de aves (Poultry by-products) & 42,50 & 41,86 & 41,22 & 40,58 & 39,94 \\
\hline Milho (Corn) & 17,45 & 13,08 & 8,72 & 4,36 & 0,00 \\
\hline Óleo de soja (Soybean oil) & 0,00 & 3,85 & 7,70 & 11,54 & 15,39 \\
\hline Suplemento (Min.+Vitam.) ${ }^{1}$ (Min + Vit supplement) & 2,00 & 2,00 & 2,00 & 2,00 & 2,00 \\
\hline Sal comum (Salt) & 0,50 & 0,50 & 0,50 & 0,50 & 0,50 \\
\hline TOTAL & 100,00 & 100,00 & 100,00 & 100,00 & 100,00 \\
\hline
\end{tabular}

${ }^{1}$ Níveis de garantia por quilograma do produto (Rovimix peixes): Vit. A, 500.000Ul; Vit. D3, 200.000Ul; Vit. E, 5.000 mg; Vit. K3, 1.000 mg; Vit. B1, 1.500 mg; Vit. B2, 1.500 mg; Vit. B6, 1.500 mg; Vit. B12, 4.000 mg; Ác. Fólico, 500 mg; Pantotenato Ca, 4.000 mg; Vit. C, 15.000 mg; Biotina, 50 mg; Inositol, 10.000; Nicotinamida, 7.000; Colina, 40.000 mg; Co, 10 mg; Cu, 500 mg; Fe, 5.000 mg; I, 50 mg; Mn, $1500 \mathrm{mg}$; Se, $10 \mathrm{mg}$; Zn, $5.000 \mathrm{mg}$.

${ }^{1}$ Levels of guarantee for kilogram of the product (Rovimix fish): Vit. A, 500,000IU; Vit. D3, 200,000 IU; Vit. E, 5, $000 \mathrm{mg} ;$ Vit. K3, 1,000 mg; Vit. B1, 1,500 mg; Vit. B2, 1,500 mg; Vit. B6, 1,500 mg; Vit. B12, 4,000 mg; Folic acid, $500 \mathrm{mg}$; Ca pantotenate, 4,000 mg; Vit. C, 15,000 mg; Biotin, 50 mg; Inosit, 10,000; Nicotinamide, 7,000; Hill, 40,000 mg; Co, 10 mg; Cu, 500 mg; Fe, 5.000 mg; I, 50 mg; Mn, 1,500 mg; Se, 10 mg; Zn, 5,000 mg.

Tabela 2 - Composição bromatológica das rações experimentais contendo diferentes níveis de energia digestível (matéria natural)

Table 2 - Chemical composition of experimental diets with different levels of digestible energy on as-fed basis

\begin{tabular}{|c|c|c|c|c|c|}
\hline \multirow{2}{*}{$\begin{array}{l}\text { Ingrediente } \\
\text { Ingredient } \\
\text { Energia digestível }(\mathrm{kcal} / \mathrm{kg})^{1} \text { (Digestible energy) }\end{array}$} & \multicolumn{5}{|c|}{$\begin{array}{c}\text { Nível de energia digestível ( } \mathrm{kcal} / \mathrm{kg}) \\
\text { Digestible energy level }\end{array}$} \\
\hline & 3300 & 3525 & 3750 & 3975 & 4200 \\
\hline Proteina bruta (Crude protein) & 43,66 & 43,68 & 43,70 & 43,72 & 43,74 \\
\hline Proteina digestível ${ }^{1,2}$ (Digestible protein) & 38,60 & 38,60 & 38,60 & 38,60 & 38,60 \\
\hline Gordura (Fat) & 12,83 & 16,66 & 20,48 & 24,31 & 28,13 \\
\hline Fibra bruta (Crude fiber) & 1,64 & 1,56 & 1,48 & 1,40 & 1,32 \\
\hline Fósforo total (Total phosphorus) & 1,20 & 1,20 & 1,20 & 1,20 & 1,20 \\
\hline Cálcio (Calcium) & 2,50 & 2,50 & 2,50 & 2,50 & 2,50 \\
\hline Amido (Starch) & 13,84 & 11,13 & 8,43 & 5,72 & 3,01 \\
\hline Metionina + cistina $($ Met + Cys $)$ & 2,22 & 2,20 & 2,19 & 2,18 & 2,17 \\
\hline Acido linoléico (Linoleic acid) & 1,95 & 3,92 & 5,90 & 7,87 & 9,85 \\
\hline Lisina (Lysine) & 2,14 & 2,16 & 2,17 & 2,19 & 2,21 \\
\hline
\end{tabular}

${ }_{1}^{1}$ Baseados nos valores de energia e digestível proposto por (Boscolo et al., 2002; Meurer et al., 2002).

2 Baseados nos valores proteína digestível proposto por Hayashi et al. (2002).

${ }^{1}$ Based on the values of digestible energy and considered by (Boscolo et al. 2002; Meurer et al., 2002).

2 Based on the values of digestible protein considered by Hayashi et al. (2002).

\section{Resultados e Discussão}

Os parâmetros físico-químicos de temperatura, oxigênio dissolvido, $\mathrm{pH}$ e condutividade elétrica da água dos aquários experimentais não apresentaram diferenças $(\mathrm{P}>0,05)$ entre os tratamentos (Tabela 3$)$, permanecendo dentro da faixa recomendada para a espécie (Popma \& Phelps, 1998).
As médias de comprimento final (CF), peso final $(\mathrm{PF})$, fator de condição e sobrevivência (SO) analisadas durante o período experimental encontram-se na Tabela 4.

As médias de peso final (PF) e comprimento final (CF) apresentaram redução linear com o aumento do nível de ED das rações. É fundamental considerar a relação proteína/energia para obtenção de bom 
desempenho dos animais (Page \& Andrews, 1973; Chou \& Shiau 1996; Lin et al., 1997; Meurer et al., 2002; Boscolo et al., 2002; Bell et al., 2003; Torstensen et al., 2004). Os resultados obtidos neste trabalho demonstraram que, entre as rações avaliadas, a que apresentou a melhor relação proteína/energia para a tilápia-do-nilo (O. niloticus) nesta fase foi a ração com $3.300 \mathrm{kcal}$ de ED/kg com 85,49 mg de PD/kcal de ED.

Meurer et al. (2002), Chou \& Shiau (1996), ElDahhar \& El-Shazly (1993) e Lovell (1989) afirmam que a energia proveniente dos lipídeos tem pouca influência no crescimento de tilápias. Observa-se neste experimento que rações com altos níveis de energia digestível, resultante da inclusão de óleo de soja, influenciaram significativamente e de forma negativa o desempenho dos animais. Foi observada relação direta entre o óleo e o amido na dieta; quanto maior a energia das rações, menor a porcentagem de amido, visto que o milho era substituído pelo óleo de soja. Provavelmente, o amido na ração fornecido pelo milho (acima de 13\% na dieta com $3.300 \mathrm{kcal}$ de ED $/ \mathrm{kg}$ de ração) foi benéfico às tilápias, embora o amido não seja considerado nutriente essencial (NRC, 1993). De acordo com Boscolo et al. (2002), a tilápia utiliza eficientemente a energia do milho, que é um alimento rico em amido e é bem aproveitado pelas tilápias, inclusive na fase inicial (Chou \& Shiau, 1996; Lin et al., 1997).

O aumento dos níveis de energia decorrentes da inclusão de lipídeos nas rações provavelmente provocou baixa taxa de ingestão de alimento e, conseqüentemente, de proteína e nutrientes essenciais, diminuindo o desempenho dos animais. Hayashi et al. (1999b), testando diferentes níveis de óleos para alevinos de carpa-capim (Ctenopharyngodon idella) observaram redução linear no desempenho dos animais à medida que aumentaram os níveis de óleo na ração. Estudos realizados por Anderson et al. (1981), citado

Tabela 3 - Valores médios dos parâmetros da água dos aquários experimentais

Table 3 - Average values of water parameters of experimental aquarium

\begin{tabular}{|c|c|c|c|c|c|c|}
\hline \multirow[t]{2}{*}{$\begin{array}{l}\text { Parâmetro* } \\
\text { Parameter }\end{array}$} & \multicolumn{5}{|c|}{$\begin{array}{c}\text { Nível de energia digestível }(\mathrm{kcal} / \mathrm{kg}) \\
\text { Digestible energy level }\end{array}$} & \multirow[t]{2}{*}{$\mathrm{CV}(\%)$} \\
\hline & 3300 & 3525 & 3750 & 3975 & 4200 & \\
\hline $\begin{array}{l}\text { Temperatura }\left({ }^{\circ} \mathrm{C}\right) \\
\text { Temperature }\end{array}$ & 25,54 & 25,50 & 25,35 & 25,46 & 25,50 & 0,51 \\
\hline $\mathrm{pH}$ & 7,96 & 7,97 & 7,98 & 7,85 & 8,01 & 1,27 \\
\hline $\begin{array}{l}\text { Condutividade elétrica }(\mu \mathrm{S} / \mathrm{cm}) \\
\text { Electric conductivity }\end{array}$ & 91,24 & 92,74 & 92,20 & 91,42 & 91,80 & 3,49 \\
\hline $\begin{array}{l}\text { Oxigênio dissolvido (mg/L) } \\
\text { Dissolved oxygen }\end{array}$ & 5,71 & 5,86 & 5,85 & 6,00 & 5,89 & 4,28 \\
\hline
\end{tabular}

* $(\mathrm{P}>0,05)$.

Tabela 4 - Desempenho de larvas de tilápia-do-nilo (Oreochromis niloticus) alimentadas com rações contendo diferentes níveis de energia digestível nas rações durante a reversão sexual

Table 4 - Performance values of Nile tilapia larvae (Oreochromis niloticus) during the sexual revertion phase fed diets with different levels of digestible energy

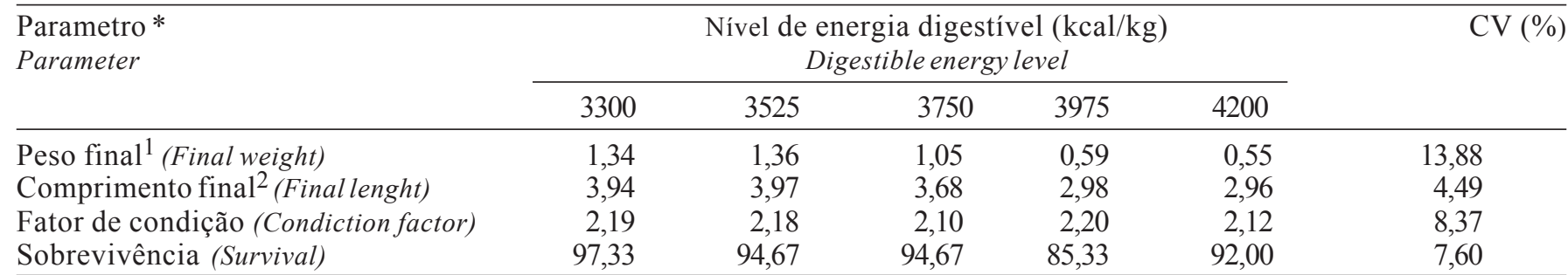

\footnotetext{
${ }^{1}$ Efeito linear; $\hat{Y}=1,68282-0,235171 x \quad r^{2}=0,80$

2 Efeito linear; $\hat{Y}=4,38795-0,294327 x \quad r^{2}=0,79$

1 Linear effect; $\hat{Y}=1,68282-0,235171 x \quad r^{2}=0,80$

2 Linear effect; $\hat{Y}=4,38795-0,294327 x \quad r^{2}=0,79$
} 
por Portz et al. (2001), demostraram que o consumo alimentar de "black bass" diminuiu com a inclusão de proteína cru e energia total na dieta. Brown et al. (1992), citados por Portz et al. (2001), observaram que o crescimento total e o ganho de peso para juvenis de "sunshine bass" diminuiu linearmente com a inclusão de proteína e energia digestível na dieta. Meurer et al. (2002) e Chou \& Shiau (1996) afirmam que a tilápia não utiliza eficientemente a energia proveniente de lipídeos em níveis acima de 5\% de inclusão na dieta. Meer et al. (1997) não observaram diferenças no desempenho de tambaqui (Colossoma macropomum) alimentados com rações contendo diferentes níveis de lipídeos, demonstrando diferenças entre espécies na utilização do óleo como fonte de energia.

A principal forma de armazenagem de energia corporal é por meio de gordura, dada as suas características de hidrofobicidade e o fácil acondicionamento nas moléculas de triacilgliceróis no interior dos adipócitos (Lehninger et al., 1995). A energia não é um nutriente, mas resulta da oxidação dos nutrientes durante o metabolismo, podendo ser liberada na forma de calor ou armazenada para uso posterior nos processos metabólicos do organismo animal (NRC, 1994). Vazzoler \& Vazzoler (1965) relatam que o fator de condição está relacionado diretamente às características fisiológicas do peixe, podendo variar de acordo com o teor de gordura, a qualidade do ambiente e idade. No entanto, os diferentes níveis de energia nas rações experimentais não influenciaram o FC dos peixes neste experimento. A taxa de sobrevivência dos peixes também não foi afetada $(\mathrm{P}>0,05)$ pelos diferentes tratamentos.

El-Dahhar \& El-Shazly (1993) observaram correlação negativa no desempenho dos animais com o aumento da ED nas rações e demonstram que, além de elevar o custo da ração, aumenta o período de cultivo dos animais e a produção de indivíduos nãouniformes, podendo acarretar disfunções metabólicas, com surgimento de doenças e conseqüente mortalidade dos indivíduos. É fundamental a participação de fontes energéticas na formulação de rações, mas a relação energia/proteína na dieta deve ser balanceada para que os peixes apresentem bom desempenho.

\section{Conclusões}

O aumento nos níveis de energia digestível em rações para larvas de tilápia-do-nilo durante a fase de reversão sexual proporciona redução no desempenho.

\section{Literatura Citada}

BELL, J.G.; MEcGHEE, F.; CAMPBELL, P.J. et al. Rpeseed oil an alternative to marine fish oil in diets of post-smolt Atlantic salmon (Salmo salar): Changes in fish fatty acid composition and effectiveness of subsequent fish oil "wash out". Aquaculture, v.218, p.515-528, 2003.

BELLAL, J.E.H.; ASSEM, H. Substution of soybean meal and oil for fish meal in pratical diets fed to channel catfish, Ictalurus punctatus (Rafinesque): effects on body composition. Aquaculture Research, v.26, p.141-145, 1995.

BORGHETTI, J.R.; OSTRENSKY, A. Estratégias e ações governamentais para incentivar o crescimento da atividade aquicola no Brasil. In: CONGRESSO SUL-AMERICANO DE AQUICULTURA, 1., 1998, Recife. Anais... Recife: Simpósio Brasileiro de Aqüicultura, 1998. p. 437-447.

BOSCOLO, W.R.; HAYASHI, C.; MEURER, F. Digestibilidade aparente da energia e nutrientes de alimentos convencionais e alternativos para a tilápia do Nilo (Oreochromis niloticus, L.). Revista Brasileira de Zootecnia, v.13, n.2, p.539-545, 2002.

BOSCOLO, W.R. Farinha de resíduos da industria de filetagem de tilápia na alimentação da tilápia do Nilo Oreochromis niloticus. Maringá: Universidade Estadual de Maringa, 2003. 83p. Tese (Doutorado em Zootecnia) Universidade Estadual de Maringá, 2003.

CHOU, B.S.; SHIAU, S.Y. Optinal dietary lipid level for growth of juvenile hibrid tilápia, Oreochromis niloticus x Oreochromis niloticus aureus. Aquaculture, v.143, n.2, p.185-195, 1996.

DEGANI, G.; REVACH, A. Digestive capabilities of three commensal fish species: carp, Cyprinus carpio L., tilapia, Oreochromis aureus X O. niloticus, and African catfish, Clarias gariepinus (Burchel 1822). Aquaculture and Fisheries Management, v.22, p.397-403. 1991.

EL-DANHHAR, A.A.; EL-SHAZLY, K. Effsct of essential amino acids (methionine and lysine) and treated oil in fish diet on growth performace and feed utilization of Nile tilapia, Tilapia nilotica (L.) Aquaculture and Fishieries Managenent, v.24, n.6, p.731-739, 1993.

HANLEY, F. The digestibility of foodstuffs and the effects of feeding selectivity determinations in tilapias (Oreochromis niloticus L.) Aquaculture, v.66, n.2, p.163-179, 1987.

HAYASHI, C.; BOSCOLO, W.R.; SOARES, C.M. et al. Exigência de proteína digestivel para larvas de tilápia do Nilo (Oreochromis niloticus), durante a reversão sexual. Revista Brasileira de Zootecnia, v.31, n.2, p.823-828, 2002.

HAYASHI, C.; BOSCOLO, W.R.; SOARES, C.M. et al. Uso de diferentes graus de moagem dos ingredientes em dietas para a tilápia do Milo (Oreochromis niloticus L.)na fase de crescimento. Acta Scientiarum, v.21,n.3, p.733-737, 1999a.

HAYASHI, C.; MEURER, F.; SOARES, C.M. et al. Utilização de diferentes níveis de gordura em dietas para alevinos de carpa capim (Ctenopharingodon idella, V). In: CONGRESSO BRASILEIRO DE ENGENHARIA DE PESCA, 11., 1999, Olinda. Anais... Olinda: Congresso Brasileiro de Engenharia de Pesca: 1999b. p.201-210.

HILDSORF,A.W.S. Genética e cultivo de tilápias vermelhas, uma revisão. Boletim Instituto de Pesca, v.22, n. 1, p.73-78, 1995.

JAUNCEY, K. Nutricional requirements. In: BEVERIDGE, M.C.M.; McANDREW, B.J. (Eds.) Tilapias: biology and exploitation. Great Britain: Kluwer Academic Publishers, 2000. p.327-375. 
LEE, S.M.; JEON, J.H.; LEE, J.Y. Effects of digestible protein and lipid levels in pratical diets on growth, protein utilization and body composition of juvenile rockfish (Sebastes schlegeli). Aquaculture, v.211, p.227-239, 2002.

LEHNIINGER, A.L.; NELSON, D.L.; COX, M.M. Princípios de bioquímica. São Paulo: Sarvier, 1995. 839p.

LOWELL, T. Nutiriton and feeding of fish. New York:Van Nostrand Reinhold, 1989. p.11-18.

LIN, J.H.; CUI, Y.; HUNG, S.S.O. et al. Effect of feeding strategy and carbohydrate source on carbohydrate utilization by white sturgeon (Acipenser transmontanus) and hybrid tilapia (Oreochromis niloticus X O. aureus). Aquaculture, v.148, p.201-211, 1997.

MARTINO, C.R.; CYRINO, J.E.P.; PORTZ, L. et al. Effect of dietary lipid level on nutricional performance of surubim (Pseudoplatistoma corruscans). Aquaculture, v.209, p.209-218, 2002.

MCGOOGAN, B.B.; REIGH, R.C. Apparent digestibility of selected ingredients in red drum (Sciaenops ocellatus) diets. Aquaculture, v.14, p.233-244, 1996.

MEER, M.B.; ZAMORA, J.E.; VERDEGEM, M.C.J. Effect of dietary lipid level on protein utilization one the size and proximate composition of fody compartments of Colossoma macropomum (Cuvier). Aquaculture Research, v.28, n.6, p.405-417, 1997.

MEURER, F.; HAYASHI, C.; BOSCOLO, W.R. et al. Lipídeos na alimentação de alevinos revertidos de tilápia do Nilo (Oreochromis niloticus L.). Revista Brasileira de Zootecnia, Viçosa, v.31, n.2, p.566-573, 2002.

MUKHOPADHYAY, N.; RAY, A.K. The apparent total and nutrient digestibility of sai seed (Shorea robusta) meal in rohu, Labeo rohita (Hamilton), fingerlings. Aquaculture Research, v.28, p.683-689, 1997.

NATIONAL RESEARCH COUNCIL - NRC. Nutrient requeriments of fish.Washington, D.C.: National Academy of Sience, 1993. 114p.

NATIONAL RESEARCH COUNCIL - NRC. Nutrient requirements of poultry. Washington, D.C.: National Academy of Science. 9.ed. 1994. 155p.
PAGE, J.W.; ANDREWS, J.W. Interaction of dietary levels of protein and energy on Channel catfish (Ictalurus punctatus). Journal of Nutrition, v.103, p.1339-1346, 1973.

POPMA, T.J.; PHELPS, R.P. Status report to commercial Tilapia producers on monosex fingerling production techniques. In; AQUICULTURA BRASIL 1998, 1., 1998, Recife. Anais... Recife; Simpósio Brasileiro de Aqüicultura, 1998. p.127-145.

PORTZ, L.; CYRINO, J.E.P.; MARTINO, R.C. Growth and body composition of juvenile largemouth bass Micropterus salmoides in response to dietary protein and energy levels. Aquaculture Nutrition, v.7, p.247-254, 2001.

SANCHES, L.E.F. Substituição do óleo de soja por óleo de tilápia e óleo de vísceras de aves em rações para alevinos de tilápia do Nilo (Oreochromis niloticus). Maringá: Universidade Estadual de Maringá, 2004. 79p. Tese (Doutorado em Zootecnia) - Universidade Estadual de Maringá, 2004.

SHIAU, S.Y. Utilization of carboidrates in warmwater fish with particular reference to tilapia, Oreochromis niloticus $\mathrm{x}$ Oreochromis aureus. Aquaculture, v.151, p.79-96, 1997.

STEFFENS, W. Princípios fundamentales de la alimentación de los peces. Madri: Acribia, 1987. 275p.

TORTENSEM, B.E.; FRAYLAND, L.; ORNSRUD, R. et al. Tailoring of a candioprotective fillet fatti acid composition of atlantic salmon (Salmo salar) fed vegetable oils. Food Chemistry, 2004. (in press)

UNIVERSIDADE FEDERAL DE VIÇOSA - UFV. SAEG Sistema para Análises Estatísticas e Genéticas (Manual do usuário).Versão 7.1 Viçosa, MG. 1997, 150p.

VAZZOLER, A.E.M.; VAZZOLER, G. Relation between condition factor and sexual developmente in Sardinella aurita. Academia Brasileira de Ciências, v.37, p.353-359, 1965.

WILSON, R.P. State of art of wawmwatr fish nuttrition. In: AQUICULTURA BRASIL 98, 1.,1998, Recife. Anais... Recife: Simpósio Brasileiro de Aqüicultura, 1998. p.375-380.

Recebido em: 14/11/04

Aceito em: 16/05/05 